\title{
Optimization on Trans-regional Electricity Transmission Scale of China's Western Renewable Energy Base: The case study of Qinghai Province
}

\author{
Bin Cai ${ }^{1}$, Yusheng Xue ${ }^{1, *}$, Yue Fan $^{2}$, Yan Wen ${ }^{3,1}$, Xinxin Yang ${ }^{4,1}$, Senlin Yang ${ }^{2}$, Zhiqing Li $^{5}$, and Haiting Wang ${ }^{2}$ \\ ${ }^{1}$ NARI Group Corporation/State Grid Electric Power Research Institute, 211106 Nanjing, China \\ ${ }^{2}$ State Grid Qinghai Electric Power Company, 810008 Xining, China \\ ${ }^{3}$ School of Electrical Engineering, Shandong University, 17923 Jinan, China \\ ${ }^{4}$ School of Electrical Engineering, Southeast University, 210000 Nanjing, China \\ ${ }^{5}$ Economic Research Institute, State Grid Qinghai Electric Power Company, 810008 Xining, China
}

\begin{abstract}
The optimization of trans-regional electricity transmission scale of China's Western renewable energy base is crucial to drive China's energy revolution. Currently, the regional power planning or optimization is aimed at minimizing the total economic cost, without taking the cost and benefit of transregional electricity transmission into account. In this paper, a regional planning model considering the cost and benefit of trans-regional electricity transmission was proposed, and the target of trans-regional electricity transmission scale by 2050 was optimized. This study analysed the influence of carbon price, fossil fuel scarcity value, accommodation cost for renewable power on the optimized result of trans-regional electricity transmission scale. Furthermore, the policy implication of the research was also analysed.
\end{abstract}

\section{Introduction}

To address the increasingly severe challenges of climate change and resource depletion, the Chinese government has actively promoted the development of clean energy. At present, China has become the world's largest renewable energy consumer, with wind power, photovoltaic and hydro-power generation ranking first in the world. In 2016, the Chinese government proposed that China would raise the proportion of non-fossil energy consumption in primary energy from less than $15 \%$ at present to $50 \%$ by 2050 in the Energy Production and Consumption Revolution Strategy (2016-2030)[1].

China's energy resources base and load centers are inversely distributed. The power consumption centers are located in the central and eastern regions, while the energy resources are rich in the western region, which has formed the power flow pattern of 'west to east electricity transmission' for a long time. In the context of clean energy transition, it has become one of the most important strategies for promoting China's energy revolution to transfer rich renewable energy resources in the western region to the central and eastern regions through (UHV) transmission.

Qinghai Province, located in the western of China, is rich in clean energy resources such as solar energy, wind energy, and water energy, which accounts for $3.3 \%$, $2.9 \%$ and $9.3 \%$ of China's exploitable resources respectively. In 2017, 2018 and 2019, State Grid Qinghai Electric Power Company have completed the innovation practice of 'Green power 7 days', 'Green power 9 days' and 'Green power 15 days' respectively. The installed capacity of Qinghai Province reached 28 million kilowatts by 2018 , among which the installed clean energy capacity accounted for $86.5 \%$. In 2018, Qinghai Province consumed 71.7 billion $\mathrm{kWh}$ electricity, and delivered around 10 billion $\mathrm{kWh}$ clean energy to central and eastern regions of China. In December 2018, the Work Plan for Qinghai Province to Build a National Clean Energy Demonstration Province (2018-2020) (hereinafter referred to as the Work Plan) was officially promulgated, which proposed the target of $100 \%$ clean energy consumption, and the construction of two ten million kilowatt renewable energy bases in Hainan and Haixi[2]. According to the Work Plan, Qinghai Province will deliver 120 billion $\mathrm{kWh}$ clean energy to the central and eastern regions annually by 2025 , accounting for $55 \%$ of the total electricity produced by this province. However, how to optimize the trans-regional electricity transmission scale in Qinghai Province in line with the national and provincial conditions by 2050 and even in the future still needs further study.

There are many related researches on provincial (or regional) energy (or power) planning based on quantitative planning models [3]. Leap, MESSAGE, TIMES/MARKAL, and other energy planning models are widely used for the decision support of renewable energy development and utilization, carbon emission

\footnotetext{
* Corresponding author: xueyusheng@sgepri.sgcc.com.cn
} 
reduction planning of Beijing [4], Shanghai [5], Jiangsu [6], Sichuan [7], Shanxi [8], Shaanxi [9] and other provinces and regions in China. However, the above studies were all aimed at minimizing the economic cost within the province or region, without considering the cost and benefit of trans-regional electricity transmission with other provinces, which was difficult to optimize the target of trans-regional electricity transmission scale.

In order to optimize the development target of renewable energy base in Western China, a regional renewable energy development planning method that takes into account the cost and benefit of trans-regional electricity transmission have been proposed in this paper. The structure of this paper is as follows: Section 2 introduces the research methods, including simulation models, objective functions and constraints. Section 3 presents the key assumptions and simulation parameters. Section 4 analyzes research results, and Section 5 provides the conclusions and policy implication.

\section{Methodology}

\subsection{Model}

Based on the Dynamic Simulation Platform for Power Market and Power System (DSPMPS) [10], which has been used for quantitative analysis of clean transition of coal-fired generation company [11] and China's energy production and consumption revolution [12], a quantitative technical-economic medium and long term power planning model involving the trans-regional power transmission was developed. The model includes coal power, wind power, photovoltaic, solar thermal, hydropower and other types of power generation technologies. The dynamic process of all kinds of power generation technologies in the whole life cycle from investment, construction, operation to decommissioning is described. The physical, economic, emission and other indicators can be calculated. The model can flexibly set the start time (e.g. the year of 2018) and the end time (e.g. the year of 2050) of simulation, and simulation step length (e.g. month, quarterly, annually, etc.). The principle of renewable energy priority for power generation dispatch is adopted in the simulation. In addition to coal power, the annual average utilization hours of power generation technologies are given as exogenous values (in which, wind power and photovoltaic need to consider abandonment).The remaining electricity demand of the entire system is provided by coal power, of which the generation sequence of coal power generators is determined according to coal consumption rate from low to high.

\subsection{Objective function and constraints}

\subsubsection{Objective function}

Large scale of clean energy delivered from western regions can reduce the coal-fired power generation, coal consumption, and carbon dioxide emission of central and eastern regions significantly. However, in addition to the investment cost of new power generation installation (wind power, photovoltaic, etc.), the cost of peak load regulation and reserve capacity paid by the whole power system to integrate the high proportion of intermittent renewable energy generation will also increase.

Therefore, when optimizing the scale of renewable power generation, the cost and benefit are need to be considered comprehensively. The objective function is shown in formula (1).

$$
\min C B_{\text {total }}=\text { Cost }+ \text { Benefit }
$$

Among them, Cost includes construction, operation and maintenance, fuel, emission cost related to power generation, fossil fuel scarcity value, transmission cost, system accommodation cost of renewable energy integration, as shown in formula (2).

$$
\begin{aligned}
\text { Cost }= & \sum_{t \in T} \sum_{n \in N}\left(\text { Const }_{n}(t)+O M_{n}(t)+\text { Fuel }_{n}(t)+C E_{n}(t)\right) \\
& +\sum_{t \in T}\left(C_{\text {scar }}(t)+C_{\text {trans }}(t)+C_{\text {accom }}(t)\right)
\end{aligned}
$$

Where $\mathrm{t}=$ time, $\mathrm{T}=$ planning horizon, $\mathrm{n}=$ energy type, $\mathrm{N}=$ number of energy types, Const $=$ construction cost of newly installed generator, $\mathrm{OM}=$ operation and maintenance cost of generator, Fuel $=$ fuel cost of coalfired power generator, $\mathrm{CE}=$ carbon emission cost of coal-fired power generator.

$\mathrm{C}_{\text {scar }}$ is the scarcity value reflecting the scarcity of fossil fuels, which is the product of the fossil fuels scarcity value per unit $\left(V_{\text {scar }}\right)$ and coal consumption $\left(\right.$ Consum $_{\text {coal }}$ ), as shown in formula (3).

$$
C_{\text {scar }}(t)=\text { Consum }_{\text {coal }}(t) * V_{\text {scar }}(t)
$$

$C_{\text {trans }}$ is the trans-region transmission cost, which is the product of trans-region transmitted electricity $\left(Q_{\text {trans }}\right)$ and transmission price per unit electricity $\left(P_{\text {trans }}\right)$.

$$
C_{\text {trans }}(t)=Q_{\text {trans }}(t) * P_{\text {trans }}(t)
$$

$C_{\text {accom }}$ is the system accommodation cost for renewable energy of power system, which is the product of the accommodation cost of per unit renewable energy generation $\left(P_{s y s}\right)$ and the power generation $\left(Q_{\text {suppl }}\right)$.

$$
C_{\text {absorb }}(t)=Q_{\text {suppl }}(t) * P_{\text {sys }}(t)
$$

Benefit is the contribution of saving the coal-fired power generation $\left(Q_{\text {saved }}\right)$ by delivering the renewable electricity to other regions (named receiving regions in this study). To make an assumption that the transregional electricity transmission is generated by clean energy, and all the saved electricity in receiving regions is coal-fired power generation. The Benefit includes three parts: reduced generation cost, reduced emission cost and saved fossil fuel scarcity value. 


$$
\text { Benefit }=\sum_{t \in T}\left(B_{\text {power }}(t)+B_{\text {emis }}(t)+B_{\text {scarity }}(t)\right)
$$

$Q_{\text {saved }}$ is equal to the product of transmission $\operatorname{loss}\left(R_{\text {transloss }}\right)$ and $Q_{\text {trans }}(t)$, as shown in formula (7).

$$
Q_{\text {saved }}(t)=Q_{\text {trans }}(t) *\left(1-R_{\text {transloss }}\right)
$$

The benefit of reduced generation cost $\left(B_{\text {power }}\right)$ is shown in formula (8). $P_{\text {coalpower }}$ is the average coal-fired power generation price of the receiving regions.

$$
B_{\text {power }}(t)=Q_{\text {saved }}(t) * P_{\text {coalpower }}(t)
$$

The benefit of reduced emission cost $\left(B_{\text {emis }}\right)$ is shown in formula (9). $E_{\text {avrelec }}$ is carbon emission per unit generation. $P_{\text {emis }}$ represents the carbon price.

$$
B_{\text {emis }}(t)=Q_{\text {saved }}(t) * E_{\text {avrelec }}(t) * P_{\text {emis }}(t)
$$

The benefit of saved fossil fuel scarcity value $B_{\text {scarity }}$ is shown in formula (10). $R_{\text {coalconsum }}$ is rate of coal consumption for electricity per unit, and $P_{\text {scarity }}$ represents the scarcity value of standard coal per unit.

$$
B_{\text {scarity }}(t)=Q_{\text {saved }}(t) * R_{\text {coalconsum }}(t) * P_{\text {scarity }}(t)
$$

\subsubsection{Constraints}

The energy balance constraint is shown in formula (11). The total power generation $Q_{\text {gene }}$ equals to the sum of the power consumption ( $\left.Q_{\text {intra }}\right)$ within the whole region and $Q_{\text {trans }}$.

$$
Q_{\text {gene }}(t)=Q_{\text {intra }}(t)+Q_{\text {trans }}(t)
$$

In addition, the inequality constraints that need to be satisfied are as follows. The proportion of renewable energy in the total generation $\left(R_{r e}\right)$ should be no less than the $R_{r e, M I N}$, as shown in formula (12).

$$
R_{r e}(t)=\frac{\operatorname{Elec}_{r e}(t)}{\operatorname{Elec}_{p r}(t)} \geq R_{r e, M I N}(t)
$$

Formula (13) indicates that the new installed capacity of each type of power generation cannot exceed the upper limit $N C_{n, M A X}$ and lower limit $N C_{n, M I N}$.

$$
N C_{n, M I N}(t) \leq N C_{n}(t) \leq N C_{n, M A X}(t)
$$

\section{Key assumption and parameters}

This simulation starts from the year of 2018 to 2050. To simplify the study, the key assumption and parameters setting are as follows:

$>$ Simulation step length is one year;
$>$ The types of clean energy includes wind power, photovoltaic power, solar thermal power and hydropower. It is assumed that the proportion of clean energy power generation in Qinghai Province will reach $100 \%$ as proposed in the work plan by 2050;

$>\quad$ The proportion of renewable energy generation and trans-regional electricity transmission keep growing at a constant rate;

$>\quad$ Carbon price, coal price, fossil fuel scarcity value and other parameters are set as fixed values;

$>$ The proportion of various power generation technologies are set as given values;

$>$ Assuming all the hydropower resources in Qinghai Province will be developed by 2050 (21870MW). The installed capacity of wind power, photovoltaic and solar thermal power by 2050 will be calculated according to the trans-regional electricity transmission scale.

$>$ It is assumed that clean energy power generation will be delivered through UHVDC lines. Therefore, the annual transmission electricity of a single line is 40 billion $\mathrm{kWh}$ (the capacity of a single UHVDC transmission line is $8000 \mathrm{MW}$ and the annual average utilization hour is 5000 hours). And the minimum step size for optimization of transregional electricity transmission is 40 billion $\mathrm{kWh}$.

$>$ The line loss rate adopts the normal value of the industry [13]. The electricity price of the receiving regions adopts the national average feed-in tariff for coal-fired generators in 2017 [14].

In addition, the input parameters of 2018 are the actual statistical data of Qinghai power system, and input parameters from 2019 to 2050 are given by investigation or reasonable assumption, see the appendix for details.

The variable to be optimized is the development scale of trans-regional electricity transmission by 2050 . Due to the uncertainty of the parameters such as the consumption cost of renewable energy, the carbon price and the scarcity value of fossil fuels, the total cost of renewable energy development plan of Qinghai Province and the selection of the optimal scale of trans-regional electricity transmission will be greatly affected. The search space for the optimization of the trans-regional electricity transmission scale is determined by the three factors.

The first $\pm 800 \mathrm{kV}$ UHVDC project that transmit clean energy from Qinghai Province is expected to be completed by the end of 2019 (Hainan - Zhumadian). So the minimum target of trans-regional electricity transmission scale by 2050 is set as 40 billion $\mathrm{kWh}$. The maximum is set as twice the target of 2025 promulgated in the Work Plan (i.e. 240 billion $\mathrm{kWh}$ ). The range of fossil fuel scarcity value is $[0,800] \mathrm{RMB} / \mathrm{tce}$, and the range of carbon price is $[0,400] \mathrm{RMB} / \mathrm{tCO}_{2}$. The system accommodation cost of Qinghai power system under different penetration of intermittent renewable energy such as wind power and photovoltaic is divided into three categories of low value, medium value and high value (see Fig. 1), which is derived from reference [15]. 
The system accommodation cost per unit renewable power will increase along with the increase of the penetration level of renewable power.

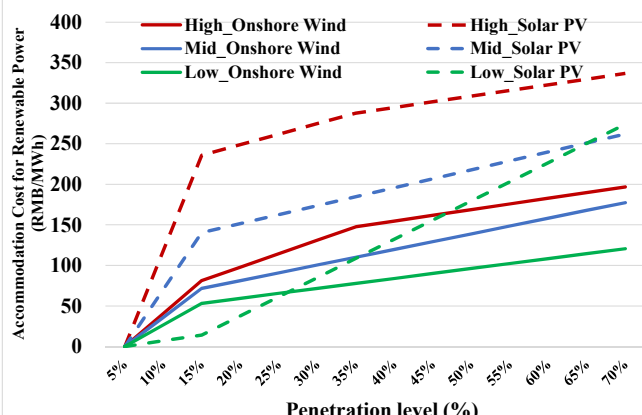

Fig. 1. Accommodation cost for renewable power under different penetration level.

\section{Results and analysis}

The simulation results shows that the total economic cost of different renewable energy development plans corresponding to different trans-regional electricity transmission scales in Qinghai Province decrease with the increase of scarcity value and carbon price, when the renewable energy accommodation cost is set as the medium value (see Fig. 2). Taking the case of transmitting 240billion KWh electricity to receiving regions by 2050 as an example (hereinafter referred to as "240 billion KWh plan", other scale of trans-regional electricity transmission by 2050 can be abbreviated in the same manner), given carbon price at 0 , when the scarcity value is increased from 0 to $800 \mathrm{RMB} / \mathrm{tce}$, the total economic cost is reduced from 1027 to 766 billion $\mathrm{RMB}$; given scarcity value at 0 , when the carbon price is expanded from 0 to $400 \mathrm{RMB} / \mathrm{tCO}_{2}$, the total economic cost is reduced from 1027 to 682 billion RMB.

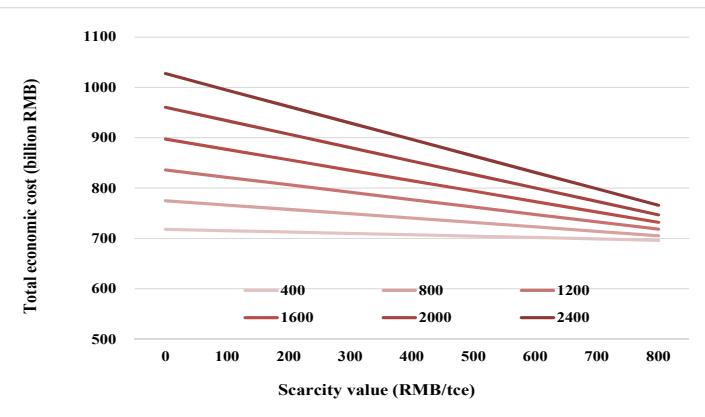

(a) Sensitivity analysis of scarcity value

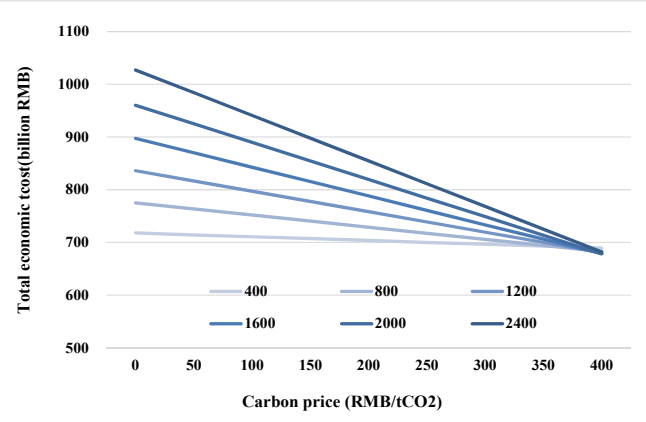

(b) Sensitivity analysis of carbon price.

Fig. 2. Impact of scarcity value and carbon price on the total economic cost

For different plans, the larger the scale of transregional electricity transmission by 2050 is, the greater impact of scarcity value and carbon price on the total economic cost is. When the scarcity value increases from 0 to $800 \mathrm{RMB} /$ tce, the total economic cost of the 240 billion KWh plan is reduced by 262 billion RMB, which is 12 times of that of the 40billion KWh plan. When carbon price increases from 0 to $400 \mathrm{RMB} / \mathrm{tCO} 2$, the total economic cost is reduced by 345 billion RMB, which is 12 times of that of the 40billion KWh plan (see Fig.2). Based on the parameter settings in this paper, the 240billion KWh plan can be the optimal choice of all the trans-regional electricity transmission development plans when the scarcity value exceeds $1200 \mathrm{RMB} /$ tce or the carbon price exceeds $450 \mathrm{RMB} / \mathrm{tCO}_{2}$.

Among these different trans-regional electricity transmission development plans, the total economic cost varies greatly with the fluctuation in renewable energy accommodation cost, fossil energy scarcity value and carbon price (see Fig.3). The larger scale of transregional electricity transmission is, the greater total economic cost will be affected by the uncertainty of the above three parameters. The smaller scale of transregional electricity transmission is, the better robustness of the scenario will be.

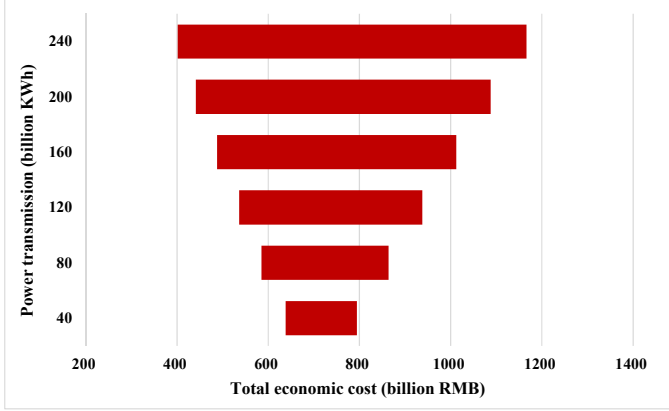

Fig. 3. Cost range under different trans-regional electricity transmission targets.

Within the range of system accommodation costs of renewable energy (low, medium and high scenarios), scarcity value $(0-800 \mathrm{RMB} /$ tce $)$ and carbon price $(0-400$ $\mathrm{RMB} / \mathrm{tCO} 2$ ) given in this study, when the scale of transregional electricity transmission is 40billion $\mathrm{KWh}$, the corresponding total economic cost is 638-795billion RMB. When the scale of trans-regional electricity transmission is 240billion $\mathrm{KWh}$, the corresponding total economic cost is 401-1166billion RMB, and its variation range is about 5 times of that under 40billion KWh plan. Table. 1 is the parameters setting of different combinations. Table. 2 shows the comparison of cost sub-items in total economic costs of the 240billion KWh plan and the above three parameters are combined to take extreme values.

Table 1. Parameters setting of different combinations 


\begin{tabular}{llll}
\hline Combination & $\begin{array}{l}\text { Accommodation } \\
\text { cost }\end{array}$ & $\begin{array}{l}\text { Carbon price } \\
\left(\mathrm{RMB} / \mathrm{tCO}_{2}\right)\end{array}$ & $\begin{array}{l}\text { Fossil fuel } \\
\text { scarcity } \\
\text { value(RMB/tce) }\end{array}$ \\
\hline$\# 1$ & High & 0 & 0 \\
\hline$\# 2$ & Low & 400 & 800 \\
\hline
\end{tabular}

Table 2. Costs and benefits of 240billion KWh plan under different parameter combinations

\begin{tabular}{|c|c|c|c|c|c|c|c|c|c|}
\hline \multirow[b]{2}{*}{ Scenario } & \multicolumn{6}{|c|}{ Cost（billion RMB） } & \multicolumn{2}{|c|}{ Benefit（billion RMB） } & \multirow{2}{*}{$\begin{array}{l}\text { Total costs } \\
\text { (billion } \\
\text { RMB) }\end{array}$} \\
\hline & $\begin{array}{l}\text { Constr } \\
\text { uction }\end{array}$ & O\&M & Fuel & $\begin{array}{l}\text { Carbon } \\
\text { emission }\end{array}$ & $\begin{array}{l}\text { Fossil fuel } \\
\text { scarcity value }\end{array}$ & $\begin{array}{l}\text { Trans- } \\
\text { regional } \\
\text { transmission }\end{array}$ & $\begin{array}{l}\text { Accommodation } \\
\text { cost for } \\
\text { renewable } \\
\text { energy }\end{array}$ & $\begin{array}{l}\text { Contributio } \\
\mathrm{n} \text { to } \\
\text { receiving } \\
\text { regions }\end{array}$ & \\
\hline Combination \#1 & 528 & 351 & 64 & 0 & 0 & 172 & 585 & 533 & 1166 \\
\hline Combination \#2 & 528 & 351 & 64 & 84 & 64 & 172 & 427 & 1288 & 401 \\
\hline Difference & 0 & 0 & 0 & 84 & 64 & 0 & 158 & 754 & 765 \\
\hline
\end{tabular}

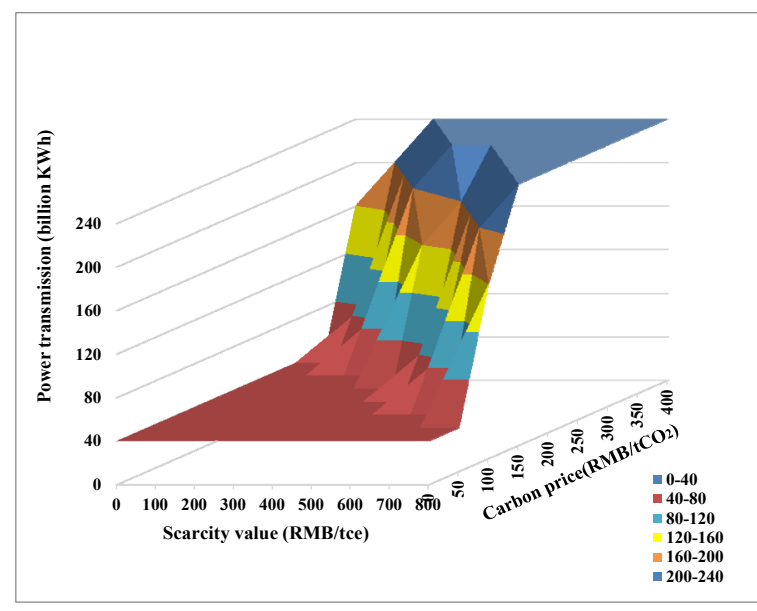

(a) Low system accommodation cost scenario

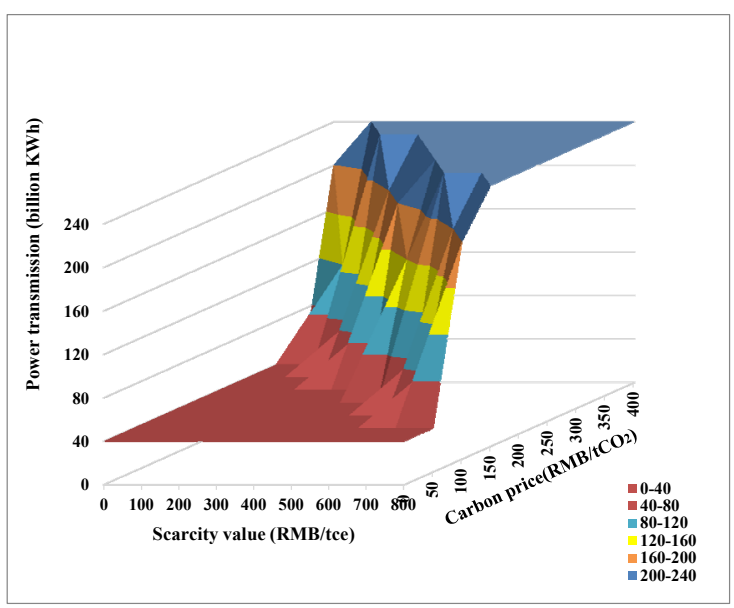

(b) Medium system accommodation cost scenario

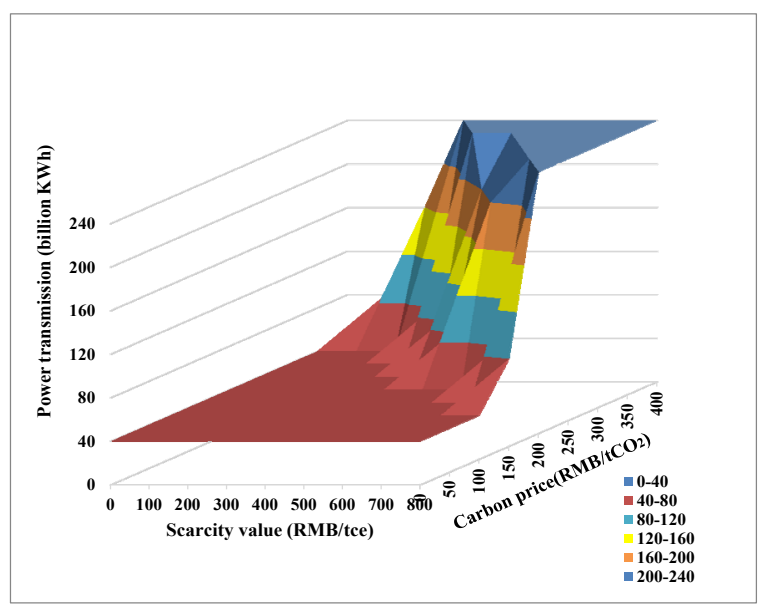

(c) High system accommodation cost scenario

Fig. 4. Optimal scale of trans-regional electricity transmission under different system accommodation cost scenarios

Fig. 4 (a), (b), and (c) illustrates the changes in the optimal trans-regional electricity transmission scale of Qinghai Province by 2050 with different scarcity value and carbon price under the low, medium and high scenarios of the renewable energy accommodation cost respectively.

Under the given renewable energy accommodation cost scenario, the optimal scale of trans-regional electricity transmission changes monotonously with the increase of scarcity value and carbon price. The higher the scarcity value and carbon price, the greater the contribution of the trans-regional electricity transmission to receiving regions, therefore, the larger the transregional electricity transmission scale should be set. When the scarcity value and carbon price are both 0 , the optimal scale of trans-regional electricity transmission under the three renewable energy accommodation cost scenarios is 40 billion $\mathrm{KWh}$; when the scarcity value is $800 \mathrm{RMB} /$ tce and the carbon price is $400 \mathrm{RMB} / \mathrm{tCO}_{2}$, the optimal scale is 240billion KWh.

Under the given scarcity value and carbon price scenario, the optimal scale of trans-regional electricity 
transmission changes non-monotonously with the increase of the renewable energy accommodation cost. When the scarcity value is $400 \mathrm{RMB} /$ tce and the carbon price is $400 \mathrm{RMB} / \mathrm{tCO} 2$, the optimal scale of transregional electricity transmission, corresponding to low, medium and high renewable energy accommodation cost, increases from 160 billion KWh to 200 billion KWh, and then decrease to 40billion KWh.

\section{Conclusion}

The optimization of the trans-regional electricity transmission scale of renewable energy bases reasonably is crucial for promoting China's energy revolution. In this study, an optimization method of regional renewable energy base considering the cost and benefit of transregional electricity transmission is proposed.

The influence of key uncertain parameters such as system cost of renewable energy, carbon emission permit price and fossil fuel scarcity value on the optimization results is analysed. The results show that the optimal scale is highly sensitive to the above three uncertainties factors.

Under the background of promoting green development and market-oriented reform, it is necessary to establish a reasonable price formation mechanism of carbon price, auxiliary service price of power system and fossil energy scarcity value evaluation system, in which the market plays a decisive role in the development of renewable energy.

This paper is a preliminary study on the optimization of trans-regional electricity transmission scale of renewable energy base. In addition to the target scale of trans-regional electricity transmission by 2050, the installed power generation capacity is also determined by the parameters (trajectory), such as the proportion of renewable energy power generation of the end year, the trajectory of renewable energy power generation during the period. In order to simplify the calculation, the above boundary conditions are given in the form of exogenous variables in this study. In the future, the above parameters (trajectory) can be taken as the variables to be optimized to support a more comprehensive study on the optimization of the trans-regional electricity transmission scale of renewable energy base.

This research work was funded by the China State Grid Corporation the Science and Technology project of "The Active Support of Power Grid to Energy Transition of Clean Energy-rich Region: A Case Study of Qinghai Province" and the Science and Technology Project of NARI Technology Co., Ltd of "Research on Key Technologies for Simulation and Evaluation of Comprehensive Energy Systems".

\section{References}

1. National Development and Reform Commission, National Energy Administration. (December 2016).
Energy Strategy of Energy Production and Consumption Revolution (2016-2030). [Online].Available:http://www.ndrc.gov.cn/zcfb/zcfb tz/201704/W020170425509386101355.pdf.

2. General Office of Qinghai Provincial People's Government. (December 2018). Work plan for Qinghai Province to build a national clean energy demonstration province (2018-2020). [Online]. Available:http://zwgk.qh.gov.cn/zdgk/zwgkzfxxgk $\mathrm{ml} /$ zfxxaqsc/201812/t20181229_32671.html.

3. C. Cormio, M. Dicorato, A. Minoia, et al. A regional energy planning methodology including renewable energy sources and environmental constraints. Renewable and Sustainable Energy Reviews, 2003; 7:99-130.

4. Y. Jia, R. Liu. Analysis of Beijing Energy Saving and Emission Reduction Strategy Based on TIMES Model. Journal of Basic Science and Engineering, 2013; 21(5):857-865.

5. Y. Yu, J. Hu, S. Zhang, et al. Study on Shanghai Energy System MARKAL Model and Scenario Analysis. Journal of Shanghai Jiaotong University, 2008; 42(03):21-25, 30.

6. Y. Wu, Y. Wang, X. Lin, et al. Energy Demand Forecast and $\mathrm{CO}_{2}$ Mitigation in Jiangsu Province. Resources and Environment in the Yangtze Basin, 2013; 22(7):908-914.

7. R. Chen, X. Zhang, J. He, et al. Provincial level renewable energy planning based on the MESSAGE model. Journal of Tsinghua University (Sci \& Tech), 2008; 48(9):145-148.

8. H. Yang, B. Du, F. Lyu, et al. Study on $\mathrm{CO} 2$ emissions in Shanxi Province base on the IPCC listing and LEAP model. Environment Pollution and Control, 2014; 36(3):103-109.

9. X. He. Forecasting Renewable Energy Development of Shaanxi Province under Subsidy Policies and Emission Limit - A Scenario Analysis Based on MARKAL. Jinan Journal (Philosophy \& Social Science Edition), 2013; 35(179):7-14,163.

10. J. Huang, Y. Xue, J. Xu, et al. Dynamic simulation platform for power market and power system part one function design. Automation of Electric Power Systems, 2011; 35(10):16-23.

11. B. Cai, Y. Xue, X. Yang, et al. Quantitative Analysis of Clean Transition Strategy of Traditional Coal-dominated GenCos. Applied Energy Symposium and Forum: CUE 2018, 5-7 June 2018, Shanghai, China.

12. Y. Wen, B. Cai, Y. Xue, et al. Assessment of Power System Low-carbon Transition Pathways Based on China's Energy Revolution Strategy. Applied Energy Symposium and Forum: CUE 2018, 5-7 June 2018, Shanghai, China.

13. National Development and Reform Commission. (August 2018). Circular of the national development and Reform Commission on issues related to the approval of transmission price of some trans- 
provincial and trans-regional special projects. [Online].Available:

http://www.ndrc.gov.cn/zcfb/zcfbtz/201809/t201809 06 897919.html.

14. National Energy Administration. (October 2018). Report on the supervision of national electricity price in 2017. [Online]. Available: http://www.nea.gov.cn/137519800 1539133305122 $\underline{1 \text { n.pdf. }}$

15. OECD. (November 2012). Nuclear Energy and Renewables-System Effects in Low-carbon Electricity Systems. [Online]. Available: https://read.oecd-ilibrary.org/nuclearenergy/nuclear-energy-andrenewables 9789264188617-en\#page19.

\section{Appendix}

Table A-1. Scenario Parameters

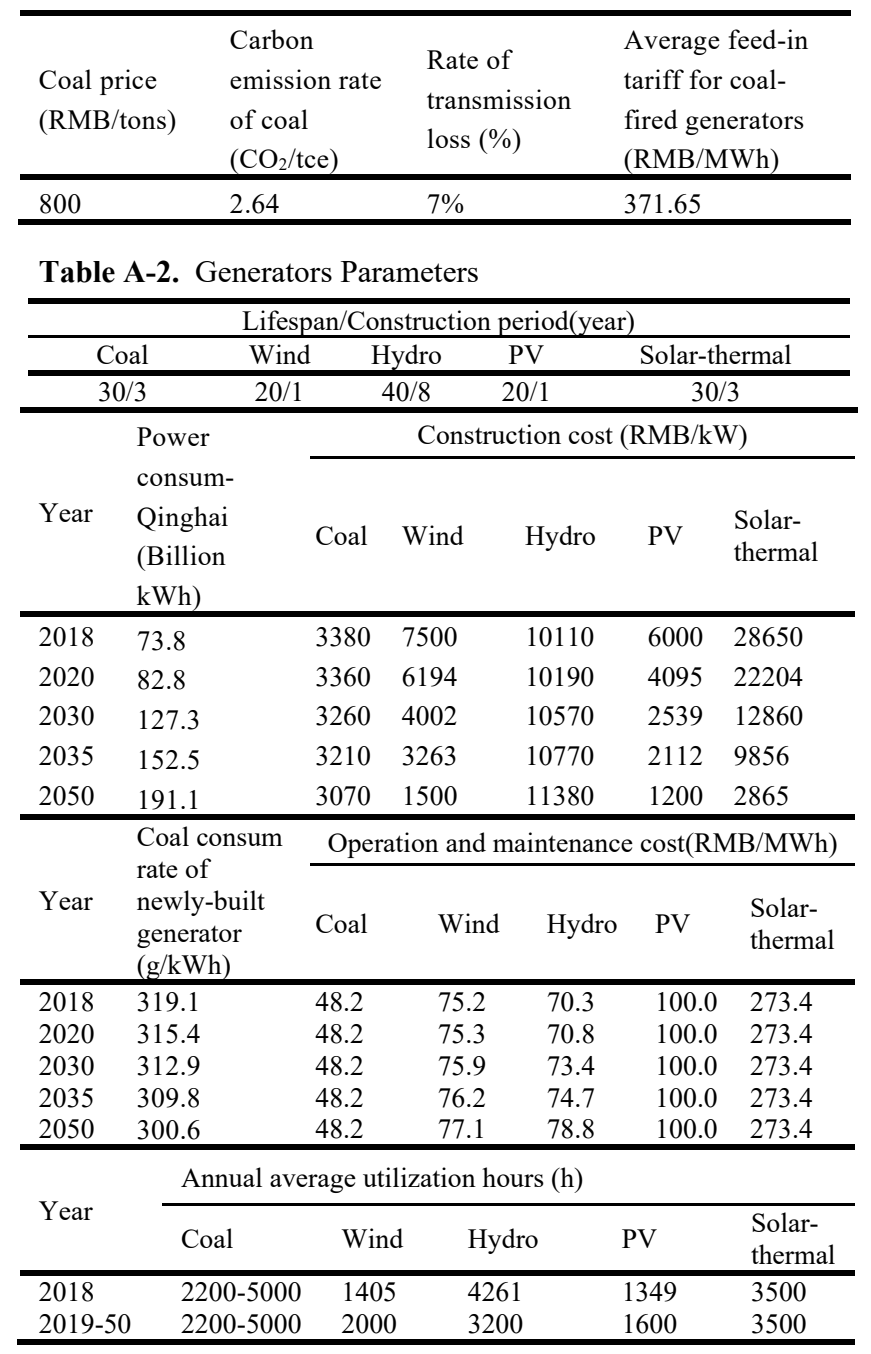

